\title{
CORRESPONDENCE.
}

\section{ON THE CALCULATION OF PREMIUMS RETURNABLE AT DEATH OR WITHDRAWAL.}

To the Editor of the Assurance Magazine.

SIR,-On looking over the pages of the last Number of the Journal I was struck with a paragraph in a letter signed J. W. Stephenson, wherein the writer professes to give a method of finding the single premium for a certain contingent benefit, with the condition that the premium shall be returnable (without interest) at death, and also in the event of the purchaser wishing to withdraw at any time before the benefit becomes payable.

Now, the determination of the premium required for the assurance of a given benefit, with the return of the premium at death, is a very simple matter; the latter contingency being perfectly susceptible of calculation. But as the contingency of having to pay a given sum on withdrawal (other than the surrender value of the policy) is not so, I was not a little curious to see how such a problem would be dealt with. The particular benefit discussed by Mr. Stephenson is a deferred annuity, and the following is, substantially, the reasoning by which he arrives at his solution.

Let $P_{x}$ denote the single premium required; and suppose $A$, the intending purchaser, deposits this amount at interest in the hands of $B$, to be held at $A$ 's disposal until the time arrives at which the annuity is wanted-say at the expiration of $n$ years. Let the yearly rate of interest which $B$ allows $A$ on his deposit be $i$ per $\mathfrak{f 1}$, which must also be the rate of interest assumed in the calculation.

With this yearly interest, amounting to $\mathrm{P}_{x} i, \mathrm{~A}$ is enabled to assure a deferred annuity (with forfeiture of premiums in the event of death) of $\mathrm{P}_{x} i \cdot \frac{\mathrm{N}_{x}-\mathrm{N}_{x+n}}{\mathrm{~N}_{x+n}}$ per annum; and at the expiration of the period of $n$ years

$$
\text { * See p. } 176 .
$$

VOL. XII. 
he can withdraw his deposit from B's hands, and with it purchase an immediate annuity of $\mathrm{P}_{x} \cdot \frac{\mathrm{D}_{x+n}}{\mathrm{~N}_{x+n}}$. The whole annuity thus acquired is $\mathbf{P}_{x} \cdot \frac{\left(\mathrm{N}_{x}-\mathrm{N}_{x+n}\right) i+\mathrm{D}_{x+n}}{\mathrm{~N}_{x+n}}$, and equating to unity, the amount to be deposited in order to secure an annuity of $f 1$ is expressed by the equation $\mathrm{P}_{x}=\frac{\mathrm{N}_{x+n}}{\left(\mathrm{~N}_{x}-\mathrm{N}_{x+n}\right) i+\mathrm{D}_{x+n}}$, which is Mr. Stephenson's formula.

By the arrangement here supposed it is evident that in the event of A's death, before the expiration of $n$ years, his representatives will receive from $B$ (at the end of the year of death) the sum of $\mathrm{P}_{x}(1+i)$, or $\mathrm{P}_{x}$ with one year's interest upon it. Now, the object of this letter is to show that the return of this sum in the event of death, and the payment of the annuity in the event of survivance, are the only contingencies really provided for by the formula above deduced; or, in fact, that the ordinary method of valuation would have conducted $\mathrm{Mr}$. Stephenson to precisely the same result as he has arrived at by his mode of solution.

The value of the deferred annuity alone is $\frac{\mathrm{N}_{x+8}}{\mathrm{D}_{x}}$, and the value of $\mathrm{P}_{x}(1+i)$, payable in the event of death, is $\mathrm{P}_{x}(1+i) \frac{\mathrm{N}_{x}-\mathrm{M}_{x+n}}{\mathrm{D}_{x}}$. Therefore,

$$
\mathrm{P}_{x}=\frac{\mathrm{N}_{x+n}}{\mathrm{D}_{x}}+\mathrm{P}_{x}(1+i) \frac{\mathrm{M}_{x}-\mathrm{M}_{x+n}}{\mathrm{D}_{x}} ;
$$

whence

$$
\mathbf{P}_{x}\left\{1-\frac{\left(\mathrm{M}_{x}-\mathrm{M}_{x+n}\right)(1+i)}{\mathrm{D}_{x}}\right\}=\frac{\mathrm{N}_{x+n}}{\mathrm{D}_{x}}
$$

and

$$
\mathrm{P}_{x}=\frac{\mathrm{N}_{x+n}}{\mathrm{D}_{x}-\left(\mathrm{M}_{x}-\mathrm{M}_{x+n}\right)(1+i)} \text {. }
$$

By substituting for $\mathrm{M}_{x}(1+i)$ and $\mathrm{M}_{x+n}(1+i)$ their equivalents $\mathrm{D}_{x}-\mathrm{N}_{x} i$ and $D_{x+n}-\mathrm{N}_{x+n} i$, we have

$$
\mathrm{P}_{x}=\frac{\mathrm{N}_{x+n}}{\left(\mathrm{~N}_{x}-\mathrm{N}_{x+n}\right) i+\mathrm{D}_{x+n}},
$$

which is the formula previously obtained.

This proves conclusively that the option of withdrawal does not enter in any way in the calculation of the premium; and indeed a little reflection will show that it cannot--for the sum which the policyholder is entitled to receive in the event of withdrawal does not admit of being fixed arbitrarily (as Mr. S. assumes), but can necessarily be no other than the surrender value of the policy (whatever it may be) determined according to the usual methods of calculation. No wonder then that (as Mr. Stephenson naively remarks "no method of deducing premiums returnable at the option, as well as on the death of a purchaser, has hitherto been published in any work on life annuities;" nor, it must be added, has Mr. Stephenson yet succeeded in supplying the omission.

It is true that, under the supposed arrangement between $A$ and $B$, the former would have the option of withdrawing his deposit from B's hands at any time before the expiration of $n$ years, and he would be entitled in 
addition to an allowance from the Office for the surrender of the deferred annuity secured by the annual interest. This, however, merely shows, that in assurances of this description the value of the policy always exceeds the premium paid upon it-a circumstance which does not depend upon the mode of computing the premium, but arises from the nature of the contingency itself.

As it is $P_{z}$ and not $P_{x}(1+i)$ that the representatives of $A$ are to receive in the event of his death, the proper formula for the proposed benefit will be

$$
P_{x}=\frac{\mathrm{N}_{x+n}}{\mathrm{D}_{x}-\left(\mathrm{M}_{x}-\mathrm{M}_{x+n}\right)}=\frac{\mathrm{N}_{x+n}}{\left(\mathrm{~N}_{x-1}-\mathrm{N}_{x+n-1}\right)(1-v)+\overline{\mathrm{D}}_{x+n}},
$$

This formula may also be deduced by $\mathrm{Mr}$. Stephenson's method, by supposing $B$ to pay the interest at the beginning instead of the end of the year; the annual interest per $f 1$ being in this case $\frac{i}{1+i}$, or $1-v$, instead of $i$.

Although Mr. Stephenson's claim to a solution of a new and impossible problem cannot be allowed, yet I think he is fairly entitled to the credit of having treated an old and perfectly practicable one in an original and striking manner.

$$
\begin{aligned}
& \text { I am, Sir, } \\
& \text { Your very obedient servant, }
\end{aligned}
$$

London, 10th May, 1865.

W. M. MAKEHAM.

THE D, N, \&c., COLUMNS OF THE EQUTTABLE EXPERIENCE. (Tabie A, Interest 3 per Cent.)

To the Editor of the Assurance Magazine.

SIR,-In looking over some of the early Numbers of the Assurance Magazine, I have found some tables in volume iii., page 366, constructed by the late Mr. Peter Hardy from the table of mortality known as the Equitable Experience; and as, in introducing these, you observe that space will be afforded to those contributors who may have authentic and original tables to offer, I am induced to send you the enclosed, in case you may consider any of them worthy of insertion. before.

The $D, N$, \&c., columns have not, that I know of, appeared in print

The tables of annuities and assurance premiums will be found to vary, between the ages of about 85 to 93 , from those of Mr. Hardy, who has not tabulated all the values between those ages quite correctly.

$$
\begin{aligned}
& \text { I am, Sir, } \\
& \text { Your obedient servant, }
\end{aligned}
$$

London.

W. MORGAN, 